JEL Classification: C32, G15

Keywords: GARCH-BEKK, volatility spillovers, stock market, currency market, Emerging Eastern Europe, Russia

\title{
Volatility Spillovers
}

\section{between Stock and Currency Markets:} Evidence from Emerging Eastern Europe*

\author{
Elena FEDOROVA - (elena.fedorova@lut.fi) \\ Kashif SALEEM - (kashif.saleem@lut.fi) corresponding author \\ both authors: \\ School of Business, Lappeenranta University of Technology, Lappeenranta, \\ Finland
}

\section{Abstract}

The purpose of this study is threefold. First, we look at the linkages between Eastern European emerging equity markets and Russia. Second, we investigate the relationships between the currency markets of Poland, Hungary, Russia, and the Czech Republic. Finally, we examine the interdependence between Emerging Eastern European and Russian equity and currency markets. We estimate a bivariate GARCH-BEKK model proposed by Engle and Kroner (1995) using weekly returns. We find evidence of direct linkages between the equity markets in terms of both returns and volatility, as well as in the currency markets. When analyzing the relationships between currency and stock markets we find unidirectional volatility spillovers from currency to stock markets. The results show clear evidence of integration of Eastern European markets within the region and with Russia as well.

\section{Introduction}

Emerging Eastern European stock markets have come to interest international financial researchers and policy-makers during the last decade. These markets have attracted the attention of international investors due to their better diversification opportunities. They have become more attractive and accessible for investment due to decreasing restrictions on transactions, a series of reforms, and increasing financial transparency. Moreover, European Union enlargement creates a unique landscape for new financial investigations and analysis.

This paper examines the stock markets in Poland, Hungary, the Czech Republic, representatives of Eastern European stock markets, and Russia, in a setting of regional influences. Our empirical analyses attempt to investigate whether and to what extent these emerging markets are integrated with each other. ${ }^{1}$ The purpose of this study is threefold. First, we look at the linkages between Eastern European emerging equity markets and Russia. Second, we investigate the relationships between the currency markets of Poland, Hungary, Russia, and the Czech Republic. Finally,

\footnotetext{
"We are grateful for comments received from participants at the 22nd Australasian Finance and Banking Conference held in Sydney, Australia in December 2009 as well as at the GSF's Joint Finance Seminar held in Helsinki in May 2009. Special thanks go to Mika Vaihekoski for his helpful comments. Elena Fedorova gratefully acknowledges financial support from the Academy of Finland, Graduate School of Finance, and the Paulo Foundation, Finland.

${ }^{1}$ By market integration we mean the interdependence or linkage between two markets or classes of assets in both the short and long run.
} 
we examine the interdependence between Emerging Eastern European and Russian equity and currency markets.

The interdependence between different equity markets has been extensively investigated. Most studies, however, have focused their attention on volatility spillovers within the developed financial markets (see, for example, Hamao et al., 1990; Theodossiou and Lee, 1993; Lin et al., 1994; Susmel and Engle, 1994; Karolyi, 1995). There are numerous studies exploring the relationships between the emerging markets of different regions, even though such work is still very scarce. For example, Worthington et al. (2000) look at the price linkages in Asian equity markets. Kasch-Haroutounian and Price (2001) examine Central Europe. Sola et al. (2002) analyze volatility links between the stock markets of Thailand, South Korea, and Brazil. More recently, Li (2007) studied the international linkages of Chinese stock exchanges. The examination of Eastern European and Russian market linkages, on the other hand, is limited and needs more investigation. Few studies explore these markets in terms of volatility and return linkages. Rare examples include Li and Majerowska (2008), Fedorova and Vaihekoski (2009), and Scheicher (2001), who study the linkages between the Czech Republic, Poland, and Hungary, whereas Saleem (2009) investigates the international linkages of the Russian market.

In the same way, the literature on the linkages between equity and currency markets mostly explains the dynamics of the currency and equity markets of developed economies (see, for example, Yang and Doong, 2004; Francis et al., 2006; Dark et al., 2005). There are some studies dealing with the emerging economies, but these are still inconclusive (see, for example, Morales, 2008; Tai, 2007; Yang and Chang, 2008). In particular, studies covering the emerging markets in Eastern Europe and Russia are very scarce.

This paper investigates the relationships between Eastern European and Russian stock and currency markets using the GARCH process, for which a BEKK representation developed by Engle and Kroner (1995) is adopted. We investigate the relationships between stock markets, between foreign exchange markets, and between stock and currency markets within one country. Our research examines whether changes on one market (for instance, a stock market) influence the performance of another market (for example, a currency market).

The sample period is from 1995 to 2008, covering Poland, Hungary, the Czech Republic, and Russia. All these countries experienced changes in their economies on the way from communist to capitalist regulation systems. Poland, Hungary, and the Czech Republic recently joined the European Union. These countries have the biggest stock markets in Emerging Eastern Europe in terms of market capitalization. On the other hand, Russia is one of the largest emerging markets in the world today. All the sample countries are growing fast given the wide range of opportunities for local and foreign investors.

We find evidence of direct linkages between the equity markets of Poland, Hungary, Russia, and the Czech Republic in terms of both returns and volatility. Similarly, interdependence between the currency markets of Poland, Hungary, Russia, and the Czech Republic is found. When analyzing the relationship between currency and stock markets we find unidirectional volatility spillovers from currency to stock markets in Poland, Hungary, and Russia. However, the Czech Republic returns 
are also found to affect the currency market. Overall, our results show clear evidence of integration of Eastern European markets within the region and with Russia as well.

The rest of the paper is organized as follows. The second section presents the theoretical background and the empirical formulation of the testable model. Section 3 introduces the sample countries, the data used in the study, and its descriptive statistics. Section 4 provides the results of the analysis. Concluding remarks are presented in Section 5.

\section{Model Specification}

Another issue addressed in this paper is the choice of model when dealing with emerging economies. The most common methodologies applied by researchers to study the volatility spillover effect are based on VAR analysis (see, for example, Syriopoulos, 2007; Lucey and Voronkova, 2006). The Autoregressive Conditional Heteroskedasticity (ARCH) process proposed by Engle (1982) and the generalized ARCH (GARCH) proposed by Bollerslev (1986) have also been extensively applied to model volatility. However, to examine the volatility linkages between two markets or assets a multivariate GARCH approach is preferred over univariate settings. The BEKK (Baba, Engle, Kraft, and Kroner) parameterization proposed by Engle and Kroner (1995) provides an appropriate framework for checking the volatility linkage between two markets. It also ensures positive definiteness of the conditional variance-covariance matrix, which early models, such as Bollerslev et al. (1988), fail to guarantee. The BEKK model complies with the hypothesis of constant correlation and allows for volatility spillover across markets.

We start our empirical specification with a bivariate $\operatorname{GARCH}(1,1)$ model that accommodates each market's returns and the returns of other markets lagged by one period. $^{2}$

$$
\begin{gathered}
r_{t}=\alpha+\beta r_{t-1}+u_{t} \\
u_{t} \mid \Omega_{t-1} \sim N\left(0, H_{t}\right)
\end{gathered}
$$

where $\boldsymbol{r}_{t}$ is an $n \times 1$ vector of weekly returns at time $t$ for each market. The $n \times 1$ vector of random errors $\mu_{t}$ represents the innovation for each market at time $t$ with its corresponding $n \times n$ conditional variance-covariance matrix $\boldsymbol{H}_{\boldsymbol{t}}$. The market information available at time $t-1$ is represented by the information set $\Omega_{t-1}$. The $n \times 1$ vector, $\boldsymbol{\alpha}$, represents the constant.

The own-market mean spillovers and cross-market mean spillovers are measured by the estimates of matrix $\boldsymbol{\beta}$ elements, the parameters of the autoregressive term. This multivariate structure thus facilitates measurement of the effects of innovations in the mean stock returns of one market on its own lagged returns and those of the lagged returns of other markets.

Given the above expression, and following Engle and Kroner (1995), the conditional covariance matrix can be stated as:

$$
H_{t}=C_{0}^{\prime} C_{0}+A_{11}^{\prime} \varepsilon_{t-1} \varepsilon_{t-1}^{\prime} A_{11}+G_{11}^{\prime} H_{t-1} G_{11}
$$

\footnotetext{
${ }^{2}$ This model is based on the bivariate GARCH(1,1)-BEKK representation proposed by Engle and Kroner (1995).
} 
where the parameter matrices for the variance equation are defined as $\boldsymbol{C}_{\mathbf{0}}$, which is restricted to be lower triangular, and two unrestricted matrices $\boldsymbol{A}_{\mathbf{1 1}}$ and $\boldsymbol{G}_{\mathbf{1 1}}$. Thus, the second moment can be represented by:

$$
H_{t}=C_{0}^{\prime} C_{0}+\left[\begin{array}{ll}
a_{11} & a_{12} \\
a_{21} & a_{22}
\end{array}\right]^{\prime}\left[\begin{array}{cc}
\varepsilon_{1, t-1}^{2} & \varepsilon_{1, t-1} \varepsilon_{2, t-1} \\
\varepsilon_{1, t-1} \varepsilon_{2, t-1} & \varepsilon_{2, t-1}^{2}
\end{array}\right]\left[\begin{array}{ll}
a_{11} & a_{12} \\
a_{21} & a_{22}
\end{array}\right]+\left[\begin{array}{ll}
g_{11} & g_{12} \\
g_{21} & g_{22}
\end{array}\right]^{\prime} H_{t-1}\left[\begin{array}{ll}
g_{11} & g_{12} \\
g_{21} & g_{22}
\end{array}\right]
$$

Following Engle and Kroner (1995) the above system can be estimated by maximum likelihood estimation, which can be optimized by using the Berndt, Hall, Hall, and Hausman (BHHH) algorithm. ${ }^{3}$ From equation (4) we obtain the conditional $\log$ likelihood function $L(\theta)$ for a sample of $T$ observations:

$$
\begin{gathered}
L(\theta)=\sum_{t=1}^{T} l_{t}(\theta) \\
l_{t}(\theta)=-\log 2 \pi-1 / 2 \log \left|H_{t}(\theta)\right|-1 / 2 \varepsilon_{t}^{\prime}(\theta) H_{t}^{-1}(\theta) \varepsilon_{t}(\theta)
\end{gathered}
$$

where $\boldsymbol{\theta}$ denotes the vector of all the unknown parameters. Numerical maximization of equation (4) yields the maximum likelihood estimates with asymptotic standard errors.

Finally, to test the null hypothesis that the model is correctly specified, or equally that the noise terms, $\boldsymbol{\mu}_{t}$, are random, the Ljung-Box Q-statistic is used. This is assumed to be asymptotically distributed as $\chi^{2}$ with $(p-k)$ degrees of freedom, where $k$ is the number of explanatory variables.

\section{Data and Descriptive Statistics}

The tests in this paper are conducted on three major emerging countries from Eastern Europe and Russia. The sample period is from January 1995 to December 2008. Our analyses are from the perspective of U.S. investors, i.e., all returns are measured in U.S. dollars. We use weekly total return indices, which are based on week-end observations of total return market indices throughout the paper.

As test assets in the analysis we utilize market portfolios from each of the sample countries. As a proxy for the market stock return we use the Datastream indices. These indices were available for the countries under investigation for the long term and have frequently been used in similar studies. The market portfolio indices include gross dividends, i.e., they measure the total pre-tax return for investors.

As a proxy for the currency market, we use the single bilateral currency exchange rates of the Polish zloty, the Czech crown, the Hungarian forint, and the Russian ruble against the U.S. dollar. As an alternative class of assets one could select, for example, the bond or derivative market. However, we chose the currency market mainly due to data availability. Moreover, the currencies of Poland, Hungary, the Czech Republic, and Russia have undergone several currency regimes (multiple devaluations and revaluations, and periods of fixed and floating exchange rates), which make them an interesting test laboratory for the tests of interdependence. Furthermore,

\footnotetext{
${ }^{3}$ We also tried the Marquardt maximum likelihood method, but the BHHH algorithm was found to perform better.
} 


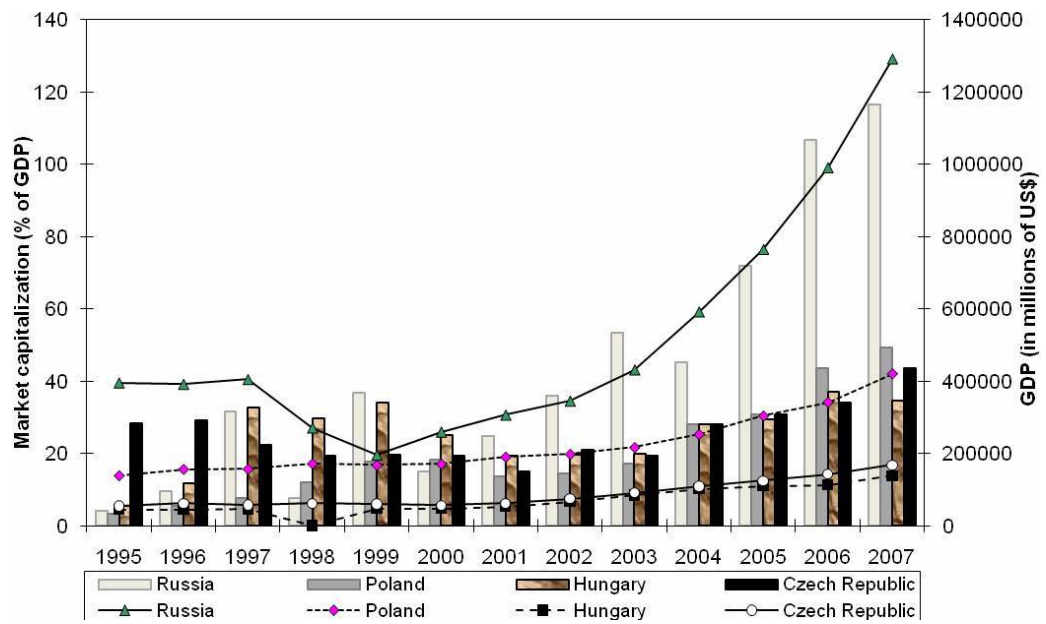

Source: World Development Indicators

the currency market is interesting from the point of view of currency risk. All data was extracted from the DataStream database.

\subsection{Sample Countries and Test Assets}

In our study we select sample countries such as Russia, Poland, Hungary, and the Czech Republic. All these economies are in transition from a communist system to a capitalist one, but in many ways their development has diverged. For example, Poland, Hungary, and the Czech Republic are relatively new European Union countries, having joined in May 2004. Russia, on the other hand, is not a member of the EU, but is one of the largest emerging markets in the world.

The stock markets of the sample countries were established during the 19th and early 20th centuries. However, during the communist regime, the stock exchanges were closed in all the countries. The first ones to open their stock markets after the end of the communist era were Hungary and Poland in mid-1991. The Russian stock market began operating in 1992. The Prague Stock Exchange in the Czech Republic was opened last, in 1993.

Figure 1 shows the stock market capitalization (in \% of GDP, column graph) and GDP (in millions of US\$, line graph) of these emerging countries over the sample period 1995-2007. The Russian Federation stands out from the others with its relatively high market capitalization, while Poland, Hungary, and the Czech Republic had an approximately equal level of capitalization over the last five years (2003-2007).

Figures 2 and 3 show the historical changes of the local return indices and exchange rates for the sample countries analyzed. The stock return graph reveals significant growth in the Russian stock market compared to the other stock markets from the middle of 1996 until the Russian financial crisis of August 17, 1998. A series of reforms was carried out at that time, including the redenomination of the Russian ruble, as reflected in Figure 3 in a significant decline of the ruble. Stock 
Figure 2 Stock Return Indices

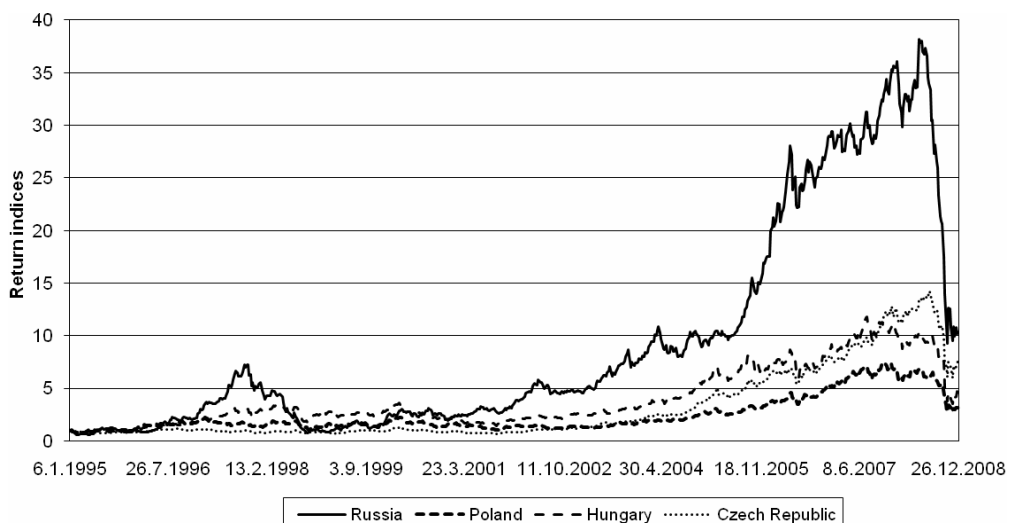

Note: All indices are scaled to 100.

Figure 3 Exchange Rates Against the USD

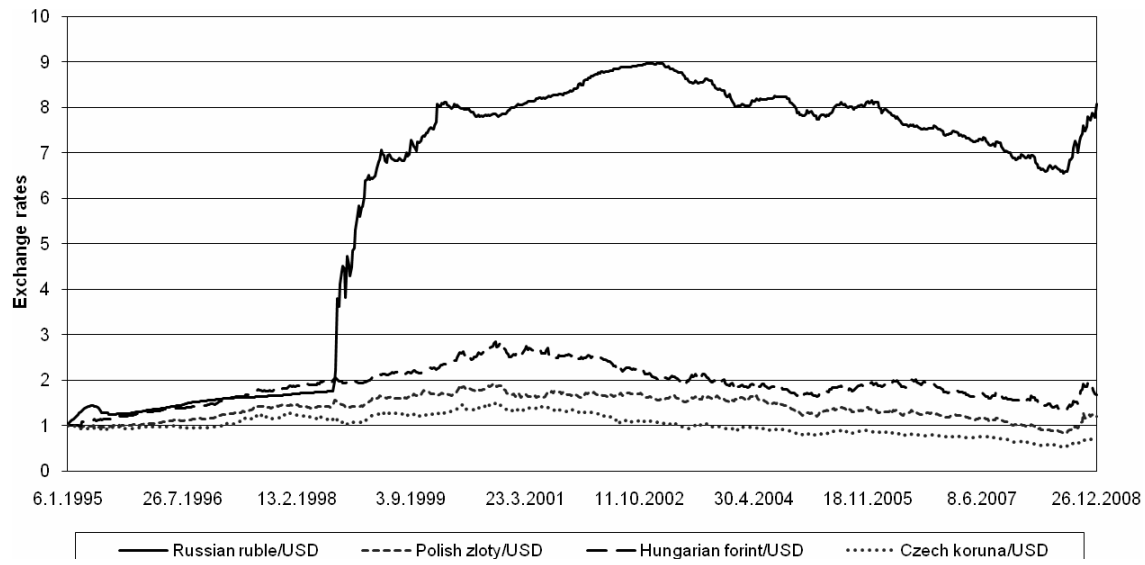

Note: All exchange rates are scaled to 1.

indices were growing and local currencies were getting stronger against the U.S. dollar thereafter. In the middle of 2008 the situation on the financial markets changed again. This phenomenon was reflected in an increase of the local currencies' exchange rates relative to the U.S. dollar. The descriptive statistics for asset returns and exchange rate changes are presented in Tables 1 and 2. Figure 4 presents the 52-week rolling-window correlation between the stock and currency markets for each country; it is evident that the correlations were volatile during the sample period.

\section{Empirical Results}

\subsection{Linkages between Equity Markets}

Our empirical results answer the theoretical questions formulated in the previous sections. First, to examine the linkages between stock markets, six pairwise 


\section{Figure 4 52-Week Rolling Correlation between Local Equity Market and Local Currency Markets Returns}

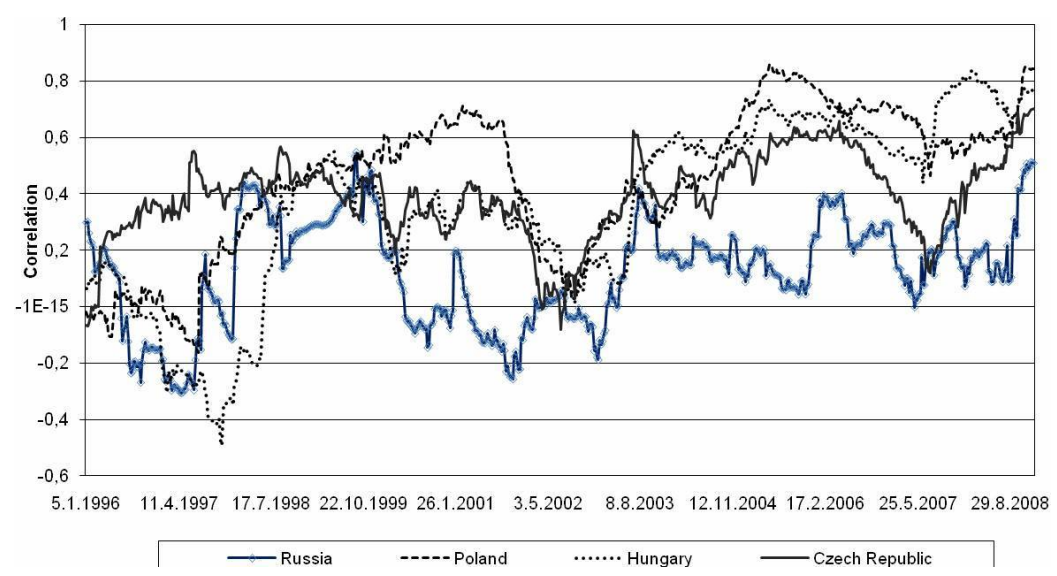

models are estimated using the bivariate $\operatorname{GARCH}(1,1)$ framework, for which a BEKK representation is adopted. The modeled pairs are Russia-Poland, Russia-Hungary, Russia-Czech Republic, Poland-Czech Republic, Poland-Hungary, and Hungary-Czech Republic. We use weekly total return indices calculated by Datastream from January 1995 to December 2008.

First, we look at matrix $\boldsymbol{\beta}$ in the mean equation - equation (1) - captured by the parameters $\beta_{i}$ in Table 3, in order to see the relationship in terms of returns within the countries in each pair. The effects of Russian stock returns are found to be considerable on all the Eastern European stock markets, as the $\beta_{1}$ parameters for all the modeled pairs with Russia are statistically significant, while the $\beta_{1}$ parameters for all the modeled pairs with Poland except for Hungary are also found to be statistically significant, suggesting that the returns in Poland also influence those in neighboring countries. Similar results are found for Hungary and the Czech Republic.

Next, we examine the estimated results of the time-varying variance-covariance equation (4) in the system. Matrices $\boldsymbol{A}$ and $\boldsymbol{G}$, reported in Table 3, help us examine the relationship in terms of volatility as stated in equation (4). The diagonal elements in matrix $\boldsymbol{A}$ capture the ARCH effect, while the diagonal elements in matrix $\boldsymbol{G}$ measure the own GARCH effect. As shown in Table 3, the estimated diagonal parameters, $a_{11}, a_{22}$ and $g_{11}, g_{22}$, are all statistically significant, indicating a strong $\operatorname{GARCH}(1,1)$ process driving the conditional variances of the six pairwise indices. In other words, own past shocks and volatility affect the conditional variance of the Polish, Czech, Hungarian, and Russian stock markets.

The off-diagonal elements of matrices $\boldsymbol{A}$ and $\boldsymbol{G}$ capture cross-market effects such as shock and volatility spillovers among the six pairs. First, we document shock transmissions between Russia and other markets. We find evidence of a unidirectional link between Russia and Poland and Russia and the Czech Republic, as well as Russia and Hungary. Interestingly the direction is from Russia to Poland, Hungary, and the Czech Republic, as only the off-diagonal parameter $a_{12}$ is statistically significant at the $5 \%$ level of significance, meaning that Russian shocks (e.g., the Rus- 


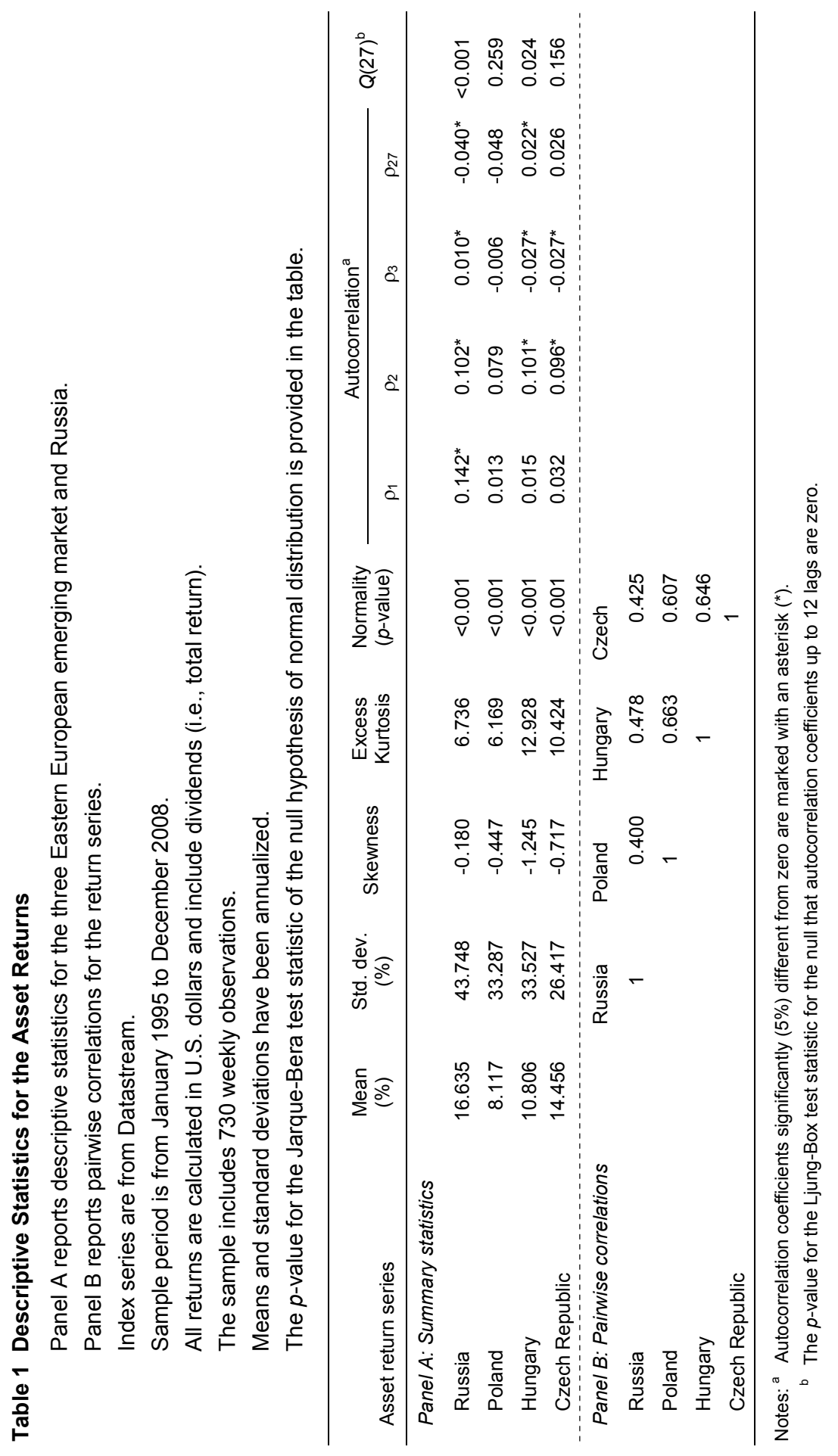




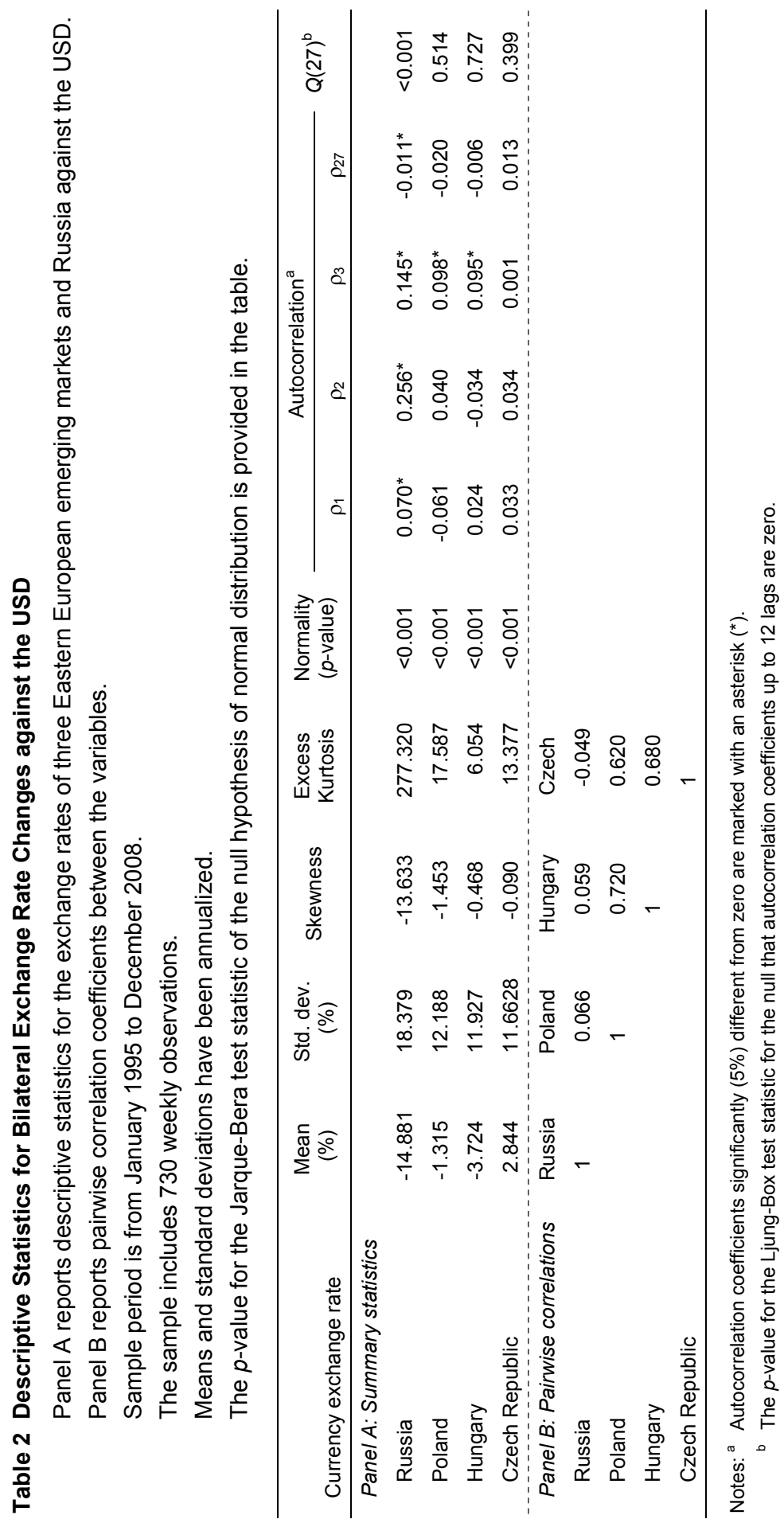

Finance a úvěr-Czech Journal of Economics and Finance, 60, 2010, no. 6 


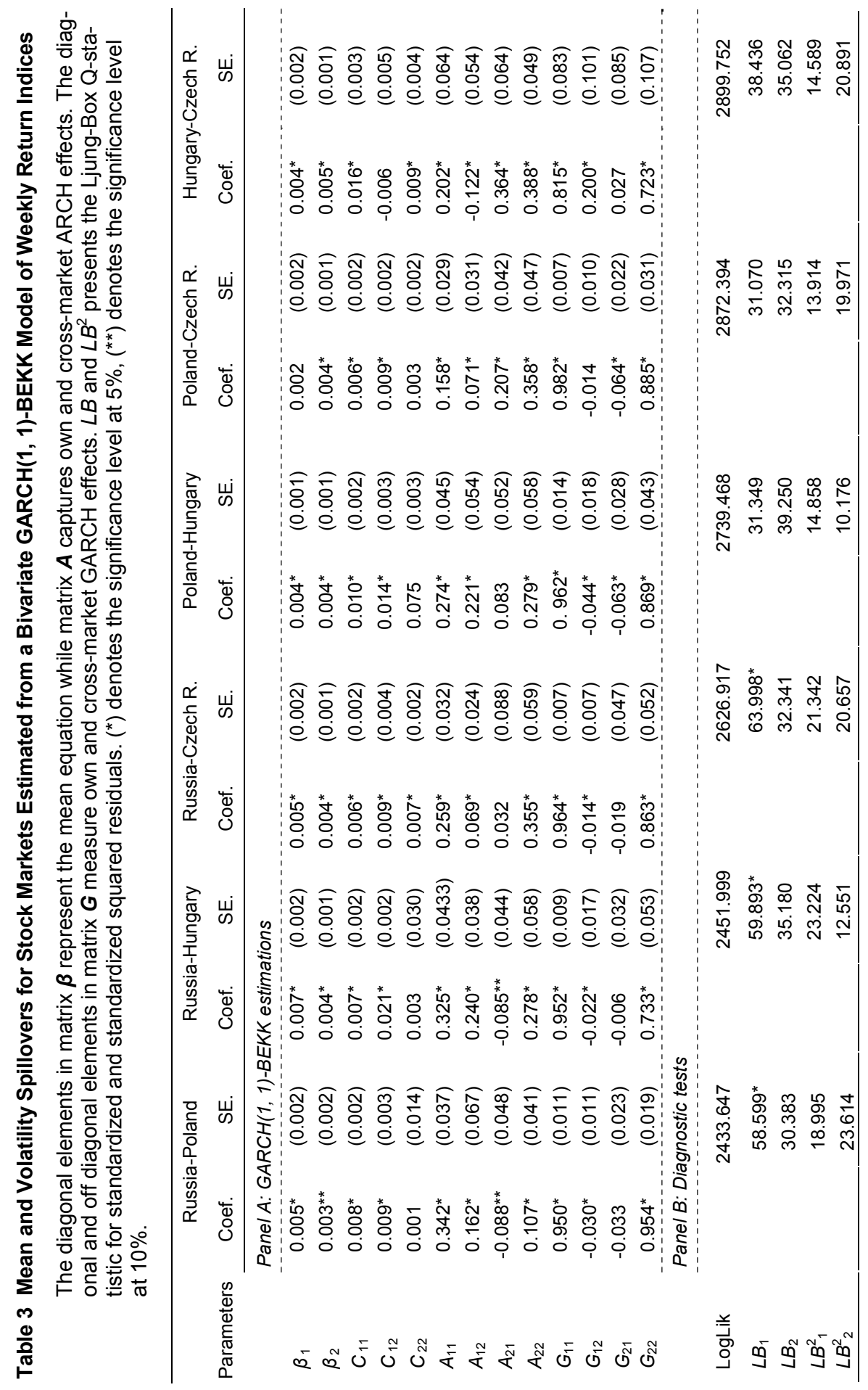




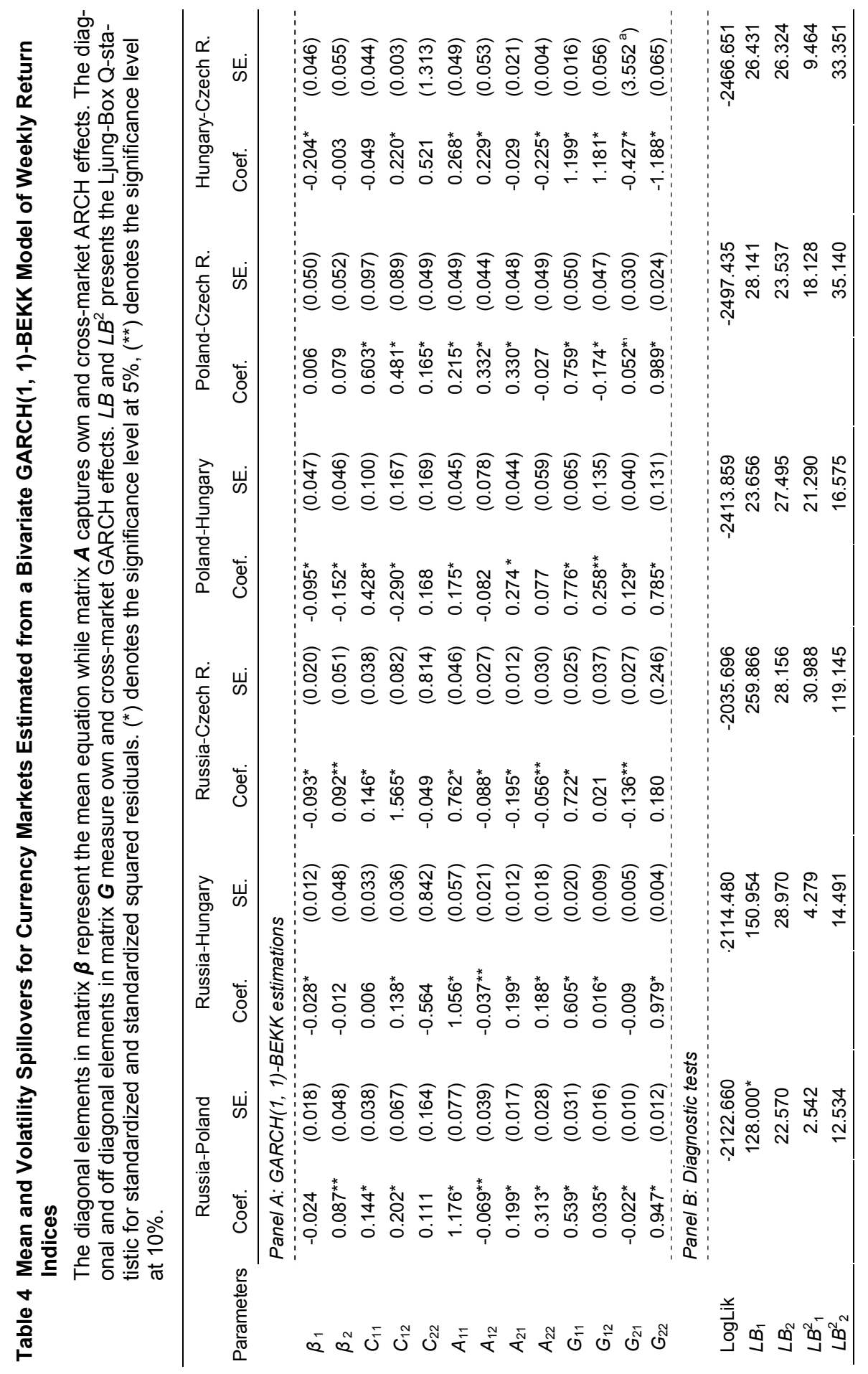




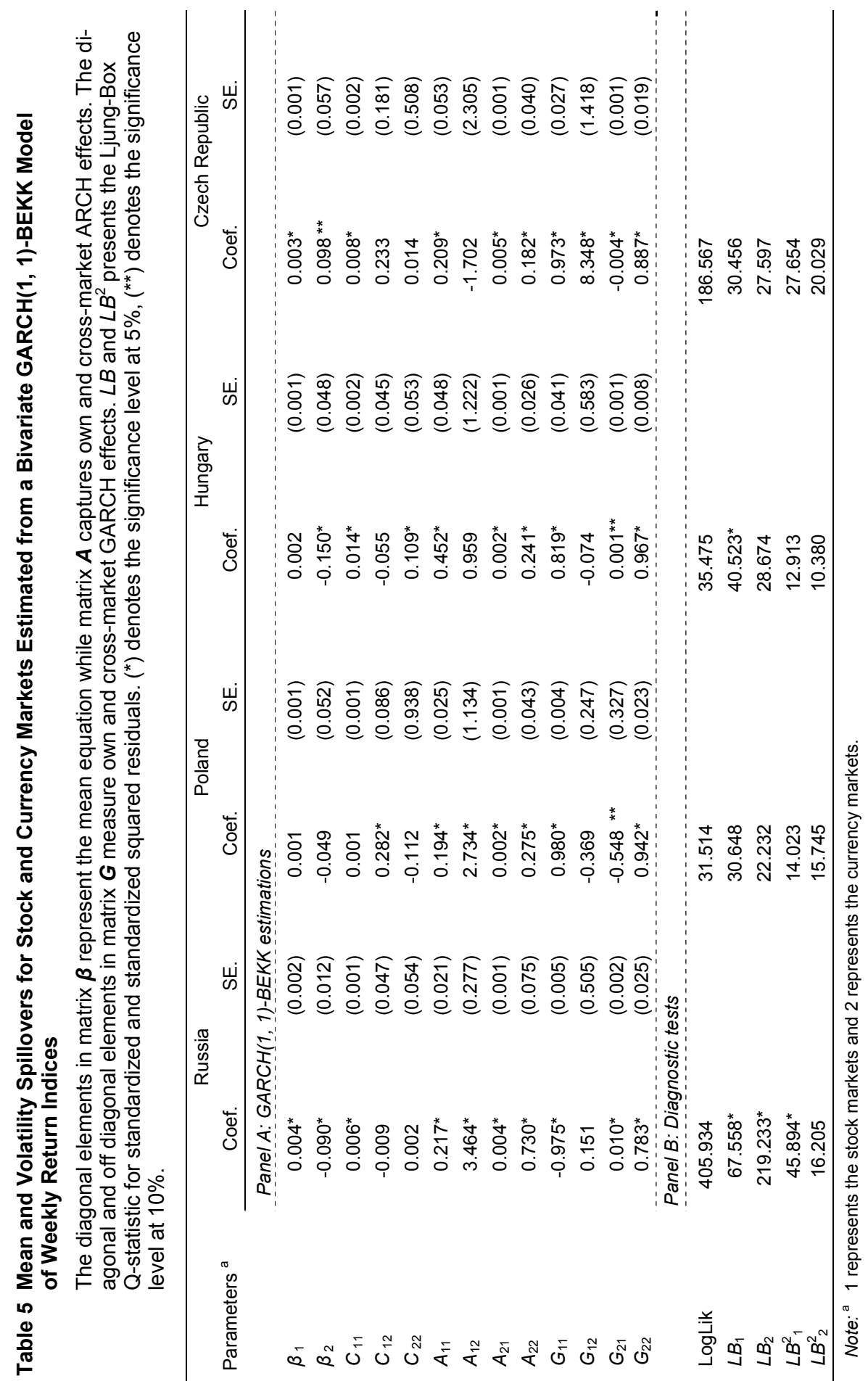


sian crisis of 1998) affected the mean returns on the Czech, Hungarian, and Polish equity markets. While analyzing shock transmissions between Poland and the Czech Republic and the Czech Republic and Hungary we find bidirectional effects. Poland and Hungary exhibit unidirectional shock transmission.

Second, we explain the volatility spillovers between the modeled pairs. We find very interesting results: for example, the Russian effect dominates in the case of Russia and Poland as well as Russia and the Czech Republic, and Russia and Hungary. The Hungarian effect dominates in the case of Hungary and the Czech Republic, and the Czech Republic volatility spillovers to Poland dominate in the case of the Poland and Czech Republic modeled pair. Between Poland and Hungary we find bidirectional spillovers. These results clearly demonstrate integration of Eastern European markets within the region and with Russia as well.

\subsection{Linkages between Currency Markets}

Next, we answer our second question: the linkages between the currency markets of selected Eastern European markets and Russia. Again, using the BEKK framework, we estimate the six pairwise models explained in the previous section.

While documenting the shock transmissions between the Russian ruble and other currencies, we find a bidirectional relation between the Russian ruble and the Czech koruna. At the same time, sudden shocks to the Polish zloty and the Hungarian forint are found to affect the movements of the Russian ruble, whereas volatility on the Russian currency market clearly has spillovers between the modeled pairs. In the case of the three selected Eastern European currency markets, we find evidence of unidirectional volatility spillovers between Poland and Hungary as well as Poland and the Czech Republic. Bidirectional volatility transmissions are found in the case of Hungary and the Czech Republic. The estimated results are reported in Table 4. Again, our results show clear evidence of integration of Eastern European currency markets within the region and with Russia as well.

\subsection{Linkages between Stock and Currency Markets}

Finally, we examine the transmission of shocks and volatility between the stock markets and currency markets of Russia, Poland, Hungary, and the Czech Republic. We present our analysis in the same fashion as in previous sections. Four pairwise models are estimated as before.

We start with the mean equation of the system. The results, reported in Table 5, show a significant effect of currency market returns on the stock market returns in Russia, Hungary, and the Czech Republic.

Next, we document the shocks and volatility spillovers represented by vectors $\boldsymbol{a}_{i j}$ and $\boldsymbol{g}_{i j}$. In all the modeled pairs we find evidence of strong ARCH and GARCH effects, as in every case the diagonal elements of matrices $\boldsymbol{A}$ and $\boldsymbol{G}, \boldsymbol{a}_{\boldsymbol{i} i}$ and $\boldsymbol{g}_{i \boldsymbol{i}}$, are highly significant, which captures within-market effects such as shock and volatility spillovers between the two assets. This indicates the suitability of our model selection.

Then we explain the shock and volatility spillovers between the modeled pairs. The off-diagonal elements of matrix $\boldsymbol{A}$ capture the cross-market shock effects. The Russian stock and currency markets as well as the Polish stock and currency 
markets show evidence of bidirectional effects, meaning that changes in the currency market also influence the stock market. In the same way, fluctuations in the stock market affect the currency market. Currency market shocks are found to dominate in the case of Hungary and the Czech Republic. Finally, we present the off-diagonal elements of matrix $\boldsymbol{G}$, which capture the cross-market volatility spillovers. In all the modeled pairs, currency market volatility is found to significantly affect the stock market. Only the Czech Republic returns are found to affect the currency market.

\section{Summary and Conclusions}

In this paper we study the relationships between the emerging markets of Eastern European and Russia in a regional setting. Both stock and foreign exchange markets are analyzed using a multivariate GARCH process. The sample period is from January 1995 to December 2008. First, we look at the linkages between the three fastest-growing Eastern European emerging equity markets, namely, Poland, Hungary, and the Czech Republic, and Russia. Second, we investigate the relationships between the currency markets of these countries. Finally, we examine the interdependence between the equity market and currency market of Poland, Hungary, Russia, and the Czech Republic. Specifically, we estimate a bivariate GARCH-BEKK model proposed by Engle and Kroner (1995) using weekly returns.

We find support for interaction of stock markets through their returns and volatilities in Poland, Hungary, Russia, and the Czech Republic. Moreover, a direct linkage is found between the currency markets of Poland, Hungary, Russia, and the Czech Republic in terms of both returns and volatility. The analyses of stock and currency markets provide evidence of unidirectional volatility spillovers from currency markets to stock markets in all the countries with the exception of the Czech Republic, where the stock market is also found to affect the currency market. These findings show that currency risk matters, which is consistent with earlier findings (see, for example, Saleem and Vaihekoski, 2008, 2010). Overall, our results show evidence of the integration of Eastern European markets within the region and with Russia as well.

\section{REFERENCES}

Bollerslev TP (1986): General autoregressive conditional heteroskedasticity. Journal of Econometrics, 31:309-328.

Bollerslev TP, Engle RF, Wooldridge JM (1988): A capital asset pricing model with time-varying covariances. The Journal of Political Economy, 96:116-131.

Dark J, Raghavan M, Kamepalli A (forthcoming): Return and volatility spillovers between the foreign exchange market and the Australian all ordinaries index. The ICFAI Journal of Applied Finance.

Engle RF (1982): Autoregressive conditional heteroskedasticity with estimates of the variance of UK inflation. Econometrica, 50:987-1008.

Engle RF, Kroner KF (1995): Multivariate simultaneous generalized ARCH. Econometric Theory, 11:122-150.

Fedorova E, Vaihekoski M (2009): Global and local sources of risk in Eastern European emerging stock markets. Finance a úvěr-Czech Journal of Economics and Finance, 59:2-19. 
Francis B, Hasan I, Hunter D (2006): Dynamic relations between international equity and currency markets: The role of currency order flow. Journal of Business, 79:219-257.

Hamao Y, Masulis R, Ng V (1990): Correlations in price changes and volatility across international stock markets. Review of Financial Studies, 3:281-307.

Karolyi G (1995): A multivariate GARCH model of international transmissions of stock returns and volatility: The case of the United States and Canada. Journal of Business and Economic Statistics, 13:11-25.

Kasch-Haroutounian M, Price S (2001): Volatility in the transition markets of Central Europe. Applied Financial Economics, 11:93-105.

Li H (2007): International linkages of the Chinese stock exchanges: A multivariate GARCH analysis. Applied Financial Economics, 17:285-297.

Li H, Majerowska E (2008): Testing stock market linkages from Poland and Hungary: A multivariate GARCH approach. Research in International Business and Finance, 22:247-266.

Lin WL, Engle RF, Ito T (1994): Do bulls and bears move across borders? International transmission of stock returns and volatility. Review of Financial Studies, 7:507-538.

Lucey B, Voronkova S (2006): The relations between emerging European and developed stock markets before and after the Russian crisis of 1997-1998. International Finance Review, 6:383-413.

Morales L (2008): Volatility spillovers between equity and currency markets: Evidence from major Latin American countries. Cuadernos de Economia, 45:185-215.

Saleem K (2009): International linkage of the Russian market and the Russian financial crisis: A multivariate GARCH analysis. Research in International Business and Finance, 23:243-256.

Saleem K, Vaihekoski M (2008): Pricing of global and local sources of risk in Russian stock market. Emerging Markets Review, 9:40-56.

Saleem K, Vaihekoski M (2010): Time-varying global and local sources of risk in Russian stock market. International Review of Economics and Finance, 19:686-697.

Sola M, Spagnolo F, Spagnolo N (2002): A test for volatility spillovers. Economics Letters, 76: 77-84.

Scheicher M (2001): The comovements of stock markets in Hungary, Poland and the Czech Republic. International Journal of Finance and Economics, 6:27-39.

Syriopoulos T (2006): Risk and return implications from investing in Emerging European stock markets. Journal of International Financial Markets, Institutions and Money, 16:283-299.

Syriopoulos T (2007): Dynamic linkages between emerging European and developed stock markets: Has the EMU any impact? International Review of Financial Analysis, 16:41-60.

Susmel R, Engle RF (1994): Hourly volatility spillovers between international equity markets. Journal of International Money and Finance, 13:3-25.

Theodossion P, Lee U (1993): Mean and volatility spillovers across major national stock markets: Further empirical evidence. Journal of Financial Research, 16:337-350.

Tai C (2007): Market integration and contagion: Evidence from Asian emerging stock and foreign exchange markets. Emerging Markets Review, 8:264-283.

Worthington AC, Katsuura M, Higgs H (2000): Price linkages in Asian equity markets and the Asian economic, currency and financial Crises. School of Economics and Finance, Queensland University of Technology, Brisbane, Queensland, Discussion Paper, no. 77.

Yang S, Doong S (2004): Price and volatility spillovers between stock prices and exchange rates: Empirical evidence from the G-7 countries. International Journal of Business and Economics, 3:139-153.

Yang Y, Chang C (2008): A double-threshold GARCH model of stock market and currency shocks on stock returns. Mathematics and Computers in Simulation, 79:458-474. 